\title{
Understanding Egyptians' Green Consumerism: An Exploratory Investigation
}

\author{
Ibrahim Al Sahouly \\ School of Business, \\ The American University in Cairo.
}

\begin{abstract}
This study contributes to the literature of Egyptian green consumerism as minimum empirical investigations that relate to this scope of research have been conducted in Egypt, especially with the younger consumers. The objective of this research is to investigate young Egyptian consumers' purchasing intention towards plastic recycled products for the purpose of providing guidelines to Egyptian companies pursuing eco consumers. Based on the outcomes of the empirical investigation, survey results showed that there is a relationship between price, labelling and intention to purchase recycled products, while no relation was found between awareness and intention to purchase. The paper proposes valuable recommendations for Egyptian marketers to adopt green strategies.
\end{abstract}

Keywords: Green Consumerism; Green Strategies; Egyptian Marketers; Eco purchase.

\section{INTRODUCTION}

The concept of green consumerism refers to consumers who are willing to buy ecologically friendly products whose contents and methods of production have a minimal impact on the environment such as buying organic food and purchasing products made of recycled materials [1]. The use of plastic in multiple industries has sparked controversy across the globe. Charles Moore, a member of Algalita Marine Research Foundation, discusses the harms arising from the use of plastic. Plastic pollution came to be through the accumulation of synthetic plastic in the environment to the extent that it creates problems for wildlife and their habitats, not to mention the impact on human populations [2]. Accordingly, it is of paramount importance to marketers to gain more insight about their targeted consumers in order to tailor green marketing strategies that adopt to the drivers for Egyptian consumers intention to purchase green products, or consumers who believe that purchasing green products or products from green companies can help the environmental problems faced today.

\section{CHALLENGES}

Despite the inconsistencies in the Egyptian market regarding eco product, addressing the younger generation segment can be an important potential to gain an insight about eco consumers. Businesses in Egypt usual target is maximizing their profits through either increasing their sales, or minimizing their costs, and in the midst of the intense competition almost all the industries face, it has become unexacting to manipulate costs to their favor. An article published in the business insider highlights the fact that it has become more economically favorable to make new plastic than recycling existing ones.

However, from a social perspective, people have become aware of the gravity of the situation and what plastic is doing to the earth, and an important pillar of any company's success is to properly react to consumer action; being more proactive. For instance, several supermarkets have stopped using plastic bags, brands such as GAP, Bodyshop and H\&M has launched a conscious line where goods are made from recycled products. Such actions should encourage 
further change in mindset and behavior. On the other hand, other entities find it easier to utilize plastic in their process and much less cost-intensive to dump wastes, and although few governments have started implementing sanction and levying fees, but very few react

As the trend towards environmental awareness increases, businesses try to search for a novel solution to decrease their wastes whilst aligning with their profit maximization outlook [3]. In order to successfully deliver a product that would be appealing to consumers, businesses have to evaluate their attitude, subjective norms, intention, behavior, perceived quality, and most importantly their awareness towards recycled products [4].

\section{LITERATURE REVIEW}

As the trend towards environmental awareness increases, businesses try to search for a novel solution to decrease their wastes whilst aligning with their profit maximization outlook [5]. In order to successfully deliver a product that would be appealing to consumers, businesses have to evaluate their attitude, subjective norms, intention, behavior, perceived quality, and most importantly their awareness towards recycled products [6].

The study conducted on Hong Kong students shows that there is a positive correlation between intention for purchase and environmental awareness [7]. This comes into agreement with two previous studies on consumer behavior [8], [9], [10] and "greener" purchase decisions [11] who also discovered a proportional relationship between consumers intent to consume their products when compared with their attitude towards environmental issues.

However, another research was conducted about consumers' behavior towards highlighted the fact that it is strenuous for them to ensure that the product is recycled, and hence companies can use this asymmetric information to their favor and mislead consumers [12]; therefore, companies should strive to minimize this discrepancy as much as possible. Signaling theory [13] argues that an eco-label from an unbiased and impartial third party signifies that the product adheres to the regulations [14] and indicates a product and/or firm's eco-friendliness. Consequently, having this label would further strengthen the direct relationship between the intention and the action of purchasing.

\section{Effect of Product-specific Features on Purchase: Price and Packaging}

Another argument raised by Subramanian and Subramanian is that consumers would consider product-specific factors which factor into decision making such as availability of substitutes [15]. This claim is supported by a cross-sectional study, using the snowballing technique where respondents referred the survey to friends and/or family members, conducted on 199 respondents classified as "More Importance on Environmentally Friendly Packaging" (MIEFP) [16].The study found that other product characteristics, such as its cost to the consumer, might impact consumers' willingness to purchase "greener" products. It also highlighted the level of importance placed on environmental awareness to its impact on customers' perception towards the packaging of the product. Therefore, it can be concluded that the awareness about environmental controversies is a crucial aspect that companies should consider within their marketing strategy. Signaling theory [17] argues that an eco-label from an unbiased and impartial third party signifies that the product adheres to the regulations [18] and indicates a product and/or firm's eco-friendliness. Consequently, having this label would further strengthen the direct relationship between the intention and the action of purchasing.

\section{Effects of Attitude on Plastic Consumption}

Moreover, a great deal of importance is placed on the intention. Although having a positive attitude is key when making purchase decisions, it must be coupled with an intention to make 
a purchase (Park and Lin, 2018). Contrary to common philosophy, empirical studies in the field of environmental consumption affirm that purchase intention is not reflected in actual purchasing behavior [19]. To further elaborate, some consumers might just like and support the notion of environmental friendliness, however, not all are participating in the market for recycled products. On the other hand, Mugge and Schoorman, in their research, highlighted the fact that there is a positive relationship between ethical stances and the purchase intention because they perceive such an action to be morally binding. What the second study demonstrates, is that for a company to successfully launch a recycled product, it would have to rely on appealing to the consumers' emotions and conscience.

However, a study conducted on 480 respondents which investigated the effect of the discerned threats which include: reduced quality and functionality [20]. The results displayed a low association between the aforementioned factors and the choice of purchase, and within the sample, some displayed openness to paying a premium above and beyond the normal selling price for recycled products.

Another study that was conducted sent 316 surveys, and 163 respondents on how you would persuade people to limit the use of disposable plastic bags and use reusable bags called "bags for life" [21]. 55.3\% of respondents said that using the environment as motivation to stop using plastic bags, the second-highest motivator is a personal utility, meaning that it's easier to transport and they are more durable. The last two motivators being social aspect, to 'look good' in front of other people by being environmentally friendly. And personal economics, making more economic sense to use reusable bags [22]. This is what consumers think are the benefits and how to convince consumers to decrease the use of plastic bags.

There are studies that suggest attitudes is associated to behaviour intentions [23]. If customers hold a positive attitude towards the use of plastic bags, then they will use plastic bags, if they hold a negative attitude towards plastic bags, then they will be less likely to use plastic bags. A couple of reasons that consumers prefer plastic bags, with convenience having the greatest impact, as well as perceived behaviour, where when companies offer plastic bags easily and at a low price, if any, people would be more likely to use it [24]. This leads to the argument, that the government should impose measures to make it less feasible to buy it which will lead to customers having a worse perception of it, will lead them to not using it as often [25].

\section{Application on the Business World}

From the business point of view, a case study was conducted on a construction company which demonstrated how workers felt negatively about recycled products especially when the costs were compared to that of "virgin" materials [26]. Moreover, there was a major concern about the secrecy of the process pertaining to recycled materials. Therefore, people need to be educated on how the process takes place and why it would be advisable for a business to consider switching. Plastic is one of the stronger, more durable materials that can be utilized in many applications at a very cost-effective price [27]. For that reason, substantial amounts of plastic are produced annually. In 2010, 389 billion plastic bottles have been produced, with $46 \%$ of these bottles used for water packaging [28]. In the past, this was not an issue. After years of mass production and increased usage of plastic, the consequences of plastic use have began to catch up to society. Due to plastic's high stability, it is extremely resistant to environmental biodegradation [29] With that being said, proper waste management needs to be conducted in order to solve this growing environmental concern. Recycling is only one main example of a waste management strategy [30]. For businesses, high levels of recycling will significantly lower material inputs and thus leading to reduced costs. The main issue here is that it is very difficult to separate plastic from organic waste. For that reason, the option of 
biodegradable plastic may significantly help in waste management [31]. There is increasing public awareness of the need for sustainable production and consumption. An empirical study conducted by Orset advises that producers should consider implementing recycling policies and adopting organic production methods [32]. Businesses can have a positive significant impact on this environmental issue and could not only help tackle this environmental dilemma, but they could also profit from it by reusing materials and in turn reducing their costs.

Another study goes in-depth of new methods that businesses use to account for the environment. Companies do 'environmental accounting' as they go along, specifically looking at their costs and which parts of their costs affect the environment. They began to infuse considerations of the environment into business aspects, without necessarily harming their product/service [33]. An example that was given about a company called Amoco's Yorktown Refinery found that $21.9 \%$ of their costs affect the environment. These costs are then analyzed to see if there are better alternatives in manufacturing inputs, or whether the information gathered on environmental costs advocates for more practical environmental management [34].

\section{Impact of Plastic on the Environment}

Plastic, in a limited amount of time, became one of the biggest concerns leading to marine debris [35] [36]. Due to that reason, Earth has faced many negative consequences including habitat damage, animals ingesting the toxic debris, disturbance of the ecosystem, as well as economic costs [37]. Research done specifically in Ohio found that the highest percentage of waste products uncovered during beach cleanups of the Lake Erie coast were of plastic bags and water bottles [38] [39]. As a result, a study was done to discover whether Ohio residents had an intention to change their behavior towards plastic in an attempt to decrease marine debris [40].This study uncovered that respondents to an internet survey were in favor of a ban on plastic bags and plastic water bottles in order to decrease the consumption of plastic and attempt to minimize marine debris. Furthermore, the respondents showed that they would be more motivated to participate in positive changes if financial incentives were given [41]. In different sectors, companies have started to use plastic debris from the ocean and recycle this plastic into new products.

Therefore, it is evident that plastic pollution is a huge concern around the world. Another study done has shown that the number of plastic production per year has gone up to 311 million tonnes in 2014 and is forecasted to increase twice as much across the coming 20 years. The same research also established that many of the plastic is dumped into the ocean, causing severe implications in the future, with statistics showing that by 2050 , the ocean will have more plastic than fish by weight [42].

To attempt at bettering this situation, many environmentalists have attempted to clean up the ocean of plastic pollution by advanced technologies to collect the plastic on a large scale, such as the non-profit organization, 'The Ocean Cleanup'. However, such projects can only be done if consumers are aware of the consequences of dumping plastic and are willing to integrate the usage of recycled products into their everyday lives. As a result, in a country such as Egypt where not many studies on environmental knowledge has been done, it is important to evaluate how customers perceive such recycled products.

Through the analysis of the literature review, it can be concluded that plastic has a grave impact on the environment to which major alterations need to be made. Moreover, research has shown that people generally have a positive attitude towards recycled products with the majority expressing intent to buy, however, the amount of the intent is not reflected on the 
level of purchase. Furthermore, the marketing mix has an effect on the level of purchase. To further elaborate, the prices of the products, as well as the packaging and labeling contribute the highest when it comes to making decisions; recycled products are expected to be cheaper, in addition to bearing a label that highlights that they are "environmentally-friendly". Lastly, holistically, the Egyptian culture is yet to reach the level of awareness developed countries have reached when it comes to recycled products and their consumption.

Accordingly, the research hypothesizes the following:

H1: There is a negative relationship between the price and the intention to purchase.

H2: There is a positive relationship between awareness and intention to purchases.

H3: There is a relationship between elaborate labeling (i.e. symbols for recycling) and the intention for purchase.

\section{METHODOLOGY}

The research population includes undergraduates from different education levels and social background. This is primarily since awareness about environmental issues is likely to be higher amongst the younger generations. The sample consists of 200 respondents. Th research sample will consist mainly of those pursuing or holding an educational degree, including university students and beyond that. We believe that this is the most adequate target population as they are more likely to be aware of environmental issues such as plastic waste and recycling.

Also they are more likely to be the generation to spear-head changes into society that will aim to help solve the problem of plastic pollution. Questionnaire is the mean of collecting data. SPSS was used, as it is the commonly used technique for data coding, entry and analysis. SPSS is a commonly used tool, to analyze quantitative data in social science research. Each member was responsible for coding and entering 50 questionnaires, and then all 150 questionnaires were combined into one file. The p-value as the main figure to test the relationship between the dependent and independent variables. According to [43], the level of marginal significance within a statistical hypothesis test is representing the probability of the occurrence of a given event. The P-value is used as an alternative to rejection point to provide the smallest level of significance at which the null hypothesis will be rejected.

\section{Reliability test}

\section{DATA ANALYSIS}

Cronbach's alpha $=0.775$

The Cronbach's alpha test is a tool for assessing the reliability of the scales used for analysis. According to our analysis, our constructs are reliable, and therefore, can be used to build the analysis to reach a conclusion.

\section{Demographics}

198 respondents answered the questionnaire, of which 142 were males and 56 were females. This does not reflect Egypt's male to female ratio, as males are considered $50.2 \%$ of Egypt's population and females $49.8 \%$.

Five different age ranges responded to the questionnaire: below 18, 18-23, 24-30, 31-40, and above 40. Given that all researchers are university students, and convenience sampling was used to distribute the questionnaire, the age group 18-23 was the dominant one in the responses, with 147 respondents falling within this age range. Followed by the age group below 18, then respondents between 24-30 and then those who are 31-40 and above 40 . This is 
also not reflective of Egypt's population demographics, as those aged between 15-24 account to $18.94 \%$, while those aged between $25-54$ account to $37.6 \%$.

As for the education, 88 of the respondents have a post-graduate diploma, 96 have a high school diploma and 14 have a university diploma. This is justified by the fact that most of the respondents are still in university, so they only have a high school diploma.

In regards to the income, 100 earn below 2000, which is justified by the fact that a lot of university students do not have a side job so their income is the allowance they get from their parents. 59 respondents earn between 2001-5000. 6 earn 5001-10000, 27 earn 10001-20000 and only 6 earn above 20000 .

\section{Parametric tests}

After conducting the one sample t-test on our variables, we found that all of them have a significance of below 5\% (0.05) so for that reason, we can accept the results and generalize them on the population. As (Table 1) reflects, the mean for awareness variable is 3.6. It is leaning more towards the agree side which means awareness has an effect on consumer's willingness to buy. The labeling variable, however, is more on the neutral side, we can deduce that on average, labeling does not have a significant effect on willingness to buy. Similarly, the price has a mean of 3.47, making it lean more towards the neutral side, so we can assume that it does not have a significant effect on willingness to buy.

(Table 1 - One sample t-tests)

\begin{tabular}{|c|c|c|}
\hline & Mean & Significance \\
\hline Total awareness & 3.65488 & 0.000 \\
\hline Total labeling & 3.35690 & 0.000 \\
\hline Total price & 3.47475 & 0.000 \\
\hline Total intention & 3.61279 & 0.000 \\
\hline
\end{tabular}

\section{Correlation}

Through SPSS analysis reflected in (Table 2), the relations between variables was found as the following: the relation between awareness and intention is moderate to low. This indicates that willingness to buy is not affected much by awareness about recycled products. On the other hand, the relationship between labeling and intention is generally quite high at 0.418 . This gives an indication that labeling has a large influence on people's willingness to buy recycled products. Price has a relatively moderate effect on intention which is coming in at 0.272. This moderate relationship shows that price has an impact on the consumer's willingness to buy.

While it is important to look at the impact that the independent variables have on the dependent variable, it is also crucial to see whether the independent variables affect one another through their relations. With that being said, our output shows that awareness has a moderately strong relationship with labeling (0.253) whereas there is a slightly weaker relationship between awareness and pricing (0.104). Thi indicates that awareness may be affected by the labeling of recycled products, and so that may cloud the impact on our dependent variable. Labelling, on the other hand, has a very weak relationship with the pricing of recycled products and so these two variables do not impact one another significantly. 
(Table 2 - Correlation)

\begin{tabular}{|c|c|c|c|c|}
\hline & Awareness & Labelling & Price & Intention \\
\hline Awareness & 1 & 0.253 & 0.131 & 0.104 \\
\hline Labelling & 0.253 & 1 & 0.073 & 0.418 \\
\hline Price & 0.131 & 0.073 & 1 & 0.272 \\
\hline Intention & 0.104 & 0.418 & 0.272 & 1 \\
\hline
\end{tabular}

\section{Significance}

According to the output, (Table 3) refelects the significance between awareness and intention is above 5\% (0.104). While we may accept this value in social sciences, it is considered high and for that reason, we cannot assume the significance of the effect of awareness on intention. The significance between labeling and intention as well as price and intention is below $5 \%$ (0.00) for both and for that reason, we can assume that there is significance in the effect of price and labeling on intention.

After looking at the effect the independent variables have on each other, we identified that the independent variables do not have any significant effect on one another. Price and awareness, however, do have a moderate significance on each other with a p-value of 0.065 . This indicates a very minute significance as our study is conducted in the field of social sciences.

Nevertheless, we can either choose to accept this significance or neglect it.

(Table 3 - Significance)

\begin{tabular}{|c|c|c|c|c|}
\hline & Awareness & Labelling & Price & Intention \\
\hline Awareness & & 0.000 & 0.065 & 0.146 \\
\hline Labelling & 0.253 & & 0.307 & 0.000 \\
\hline Price & 0.131 & 0.307 & & 0.000 \\
\hline Intention & 0.104 & 0.000 & 0.000 & \\
\hline
\end{tabular}

\section{Regression}

Model Summary: R square $=0.234$ ANOVA: Sig $=0.000$

(Table 4 - Regression)

\begin{tabular}{|c|c|c|}
\hline & Beta (Standardized) & Significance \\
\hline Awareness & -0.032 & 0.627 \\
\hline Labeling & 0.408 & 0.000 \\
\hline Price & 0.246 & 0.000 \\
\hline
\end{tabular}

Durbin Watson= 2.029

(Table 4) reflects that when interpreting the R-square to measure the importance of the chosen variables in predicting the behavior of our dependent variable, our R-squared value came to be 0.234. In general, we would consider this a relatively high value in social science and therefore it shows that the factors of awareness, labeling and price and useful interpreters. Moreover, the negative beta of -0.032 suggests that there is a negative correlation, as any unit change in awareness, there is a -0.032 change in intention to purchase. However, as the significance level is higher than $5 \%$, we, therefore, reject awareness. On the other hand, the opposite is true for the labeling and price, as they are both positive, so any unit change in either would result in a 0.408 and 0.246 change relatively. Additionally, their significance level is 0 , which means that they are accepted. Overall, the new conceptual model is pricing and labeling. Finally, the 
Durbin Watson value of 2.029 means that there is no autocorrelation detected in the sample. Table 5 shows an overall overview of the results of hypothesis testing.

(Table 5 - Final results)

\begin{tabular}{|l|l|}
\hline \multicolumn{1}{|c|}{ Hypotheses } & \multicolumn{1}{c|}{ Results } \\
\hline $\begin{array}{l}\text { H1: There is a negative relationship between } \\
\text { the price and the intention to purchase }\end{array}$ & $\begin{array}{l}\text { P-Value=0.000 } \\
\text { Correlation coefficient=0.272 } \\
\text { There is a relationship between price and } \\
\text { intention to purchase recycled products } \\
\text { Hypothesis is accepted }\end{array}$ \\
\hline $\begin{array}{l}\text { H2: There is a positive relationship between } \\
\text { awareness and intention to purchases } \\
\text { increases }\end{array}$ & $\begin{array}{l}\text { P-Value=0.146 } \\
\text { Correlation coefficient=0.104 } \\
\text { There is no relationship between awareness and } \\
\text { intention to purchase because of the pricing and } \\
\text { labelling effect. Hypothesis is rejected }\end{array}$ \\
\hline $\begin{array}{l}\text { H3: There is a relationship between elaborate } \\
\text { labeling (i.e. symbols for recycling) and the } \\
\text { intention for purchase }\end{array}$ & $\begin{array}{l}\text { P-Value=0.000 } \\
\text { Correlation coefficient=0.418 } \\
\text { There is a relationship between labelling and } \\
\text { intention to purchase recycled products. Hypothesis is } \\
\text { accepted }\end{array}$ \\
\hline
\end{tabular}

\section{DISCUSSION}

From the analysis of $\mathrm{H} 1$, our target consumers are not affected by price, with consumers as the mean value is leaning towards neutral. Therefore, consumers will not consider price as a main component on their intention to buy recycled products. Research results are parallel with the literature we have reviewed. The literature indicates that price has a very low association with buying recycled products, and some within the sample have shown a willingness to pay a premium for recycled products. Research results have further shown that consumers do not put a large emphasis on price for recycled products. The analysis of $\mathrm{H} 2$ showed that consumers did agree that their intention to buy products stem from being aware of current environmental problems, and how their purchases will affect the environment; accordingly, companies should consider this aspect, by spreading more awareness of environmental controversies, as to convince and persuade customers to buy their recycled products. The results from our research did draw some parallels. The literature highlighted the importance of environmental analysis on customers perception towards the packaging of the products. The research in this study did find that environmental awareness is important towards customers perceptions towards the packaging, but not at the same level of importance.

he analysis of H3 showed that labelling did not really influence consumers' willingness to buy recycled products. Labelling does not really affect the consumers willing to buy according to our results, meaning that companies should find alternative ways to attract consumers to buy recycled products. The results from our research contradict what we had deduced from the literature, which further highlighted the importance of labelling on people's perception towards recycled products. The research suggested that labelling does not really affect consumers' willingness to buy eco products in Egypt. 


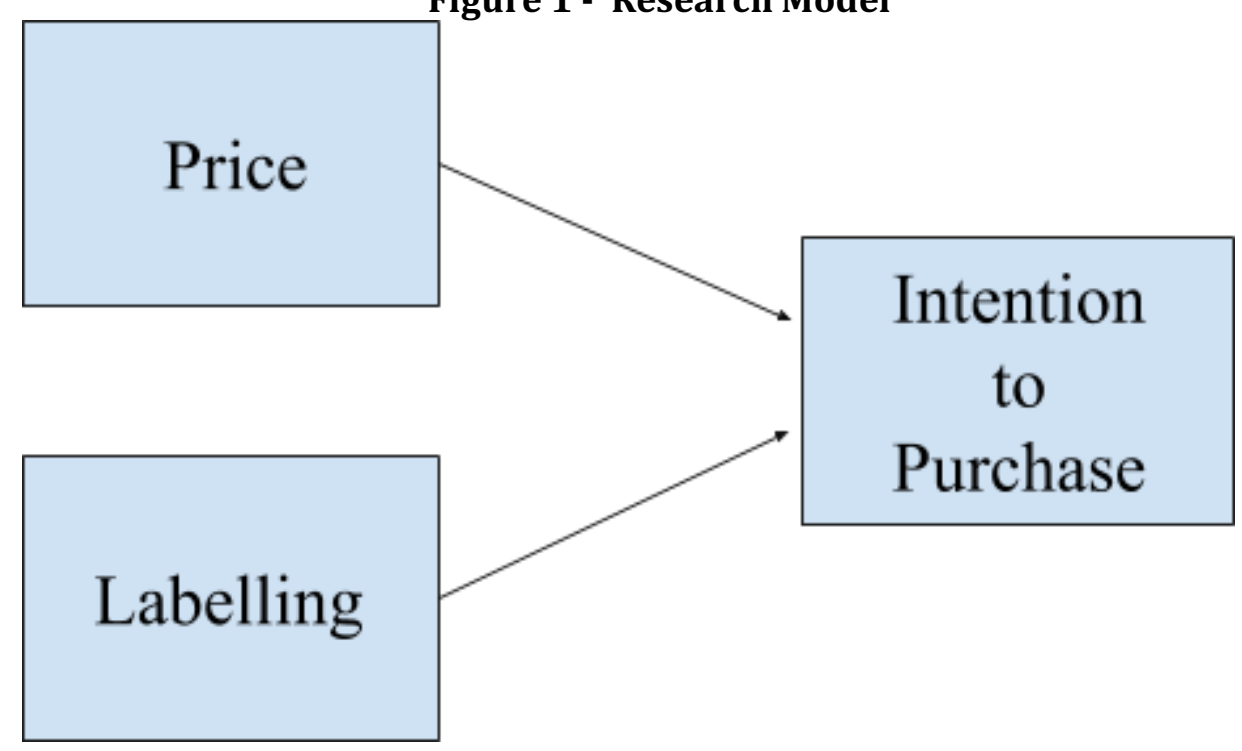

Our conducting our research, we found that we were able to accept the hypotheses regarding the price of recycled products and the labelling of recycled products and their effect on intention to purchase. However, results had shown that the independent variable (awareness) does not have an effect on the consumer's intention to purchase recycled products. This leads us to reject that variable as to having any effect on intention to purchase and gives us a model as shown in figure 1.

\section{CONCLUDING REMARKS FOR MARKETERS}

The main aim of this study was to explore the attitudes of Egyptians, mainly the younger generations towards the consumption for green products. The study focused on how three variables; price, packaging and awareness affected the willingness to buy recycled products (green consumerism). This study aimed at testing all three hypotheses to find at the end that only one was rejected and two were accepted. It can be concluded that both the price as well as the labelling and packaging of a recycled product did affect somehow the consumer's willingness to buy. However, the level of awareness as a variable was deemed insignificant throughout the research.

It is worth noting that this study was exploratory in nature to give a general overview to Egyptian marketers to gain more insight about their targeted consumers in order to tailor green marketing strategies that adopt to the drivers for Egyptian consumers intention to purchase green products, or consumers who believe that purchasing green products or products from green companies can help the environmental problems faced today. Accordingly, it is strongly recommended to duplicate this study including a diverse sample in addition to exploring more marketing variables that might be of potential interest to a diverse niche of Egyptian marketers.

Consequently, and in light of the above, the researchers recommend marketers to:

- Increase effort in spreading awareness of environmental problems, as to better inform their consumers.

- Consider price fluctuations and how they affect consumer willingness to buy, so therefore companies need to regard their prices of recycled items at a moderate range as to attract customers as well as gain a proper profit margin.

- Focus marketing efforts on packaging and labelling to make it more appealing as to attract customers to purchase recycled products due to the significance found. 
- Increase marketing activities in informing consumers about the danger society faces due to environmental issues, and convey that reusing and recycling is the way to go for the future.

- Rebrand recycle products to be at the TOMA (top of mind awareness) of customers by redirecting the way they perceive recycled products through different promotional elements.

\section{References}

Gaur, Jighyasu et al., (2015). Drivers of consumer purchase intentions for remanufactured products A study of Indian consumers relocated to the USA. Qualitative Market Research: An International Journal Vol. 18 No. 1, 2015 pp. 30-47.

Moore, Z. E., \& Patton, D. (2019). Risk assessment tools for the prevention of pressure ulcers. Cochrane Database of Systematic Reviews, (1).

Gaur, Jighyasu et al., (2015). Drivers of consumer purchase intentions for remanufactured products A study of Indian consumers relocated to the USA. Qualitative Market Research: An International Journal Vol. 18 No. 1, 2015 pp. 30-47.

Sun, Y., Wang, S., Li, J., Zhao, D., \& Fan, J. (2017). Understanding consumers' intention to use plastic bags: using an extended theory of planned behaviour model. Natural Hazards, 89(3), 1327-1342. doi: 10.1007/s11069-0173022-0

Colhoun, H., \& Prescott-Clarke, P. (1994). Health Survey for England 1994: a survey carried out on behalf of the Department of Health. HMSO.

Sun, Y., Wang, S., Li, J., Zhao, D., \& Fan, J. (2017). Understanding consumers' intention to use plastic bags: using an extended theory of planned behaviour model. Natural Hazards, 89(3), 1327-1342. doi: 10.1007/s11069-0173022-0.

Sun, Y., Wang, S., Li, J., Zhao, D., \& Fan, J. (2017). Understanding consumers' intention to use plastic bags: using an extended theory of planned behaviour model. Natural Hazards, 89(3), 1327-1342. doi: 10.1007/s11069-0173022-0.

Ajzen I (1991) The theory of planned behavior. Organ Behav Hum Decis Process 50(2):179-211 Ramayah T, Lee JWC, Lim S (2012) Sustaining the environment through recycling: an empirical study. J Environ Manag 102:14114.

Ajzen, I., \& Fishbein, M. (1975). A Bayesian analysis of attribution processes. Psychological bulletin, 82(2), 261

Sheppard, B. H., Hartwick, J., \& Warshaw, P. R. (1988). The theory of reasoned action: A meta-analysis of past research with recommendations for modifications and future research. Journal of consumer research, 15(3), 325343.

Schlegelmilch, B. B., Bohlen, G. M., \& Diamantopoulos, A. (1996). The link between green purchasing decisions and measures of environmental consciousness. European journal of marketing.

Sønderskov, K. M., \& Daugbjerg, C. (2011). The state and consumer confidence in eco-labeling: organic labeling in Denmark, Sweden, The United Kingdom and The United States. Agriculture and human values, 28(4), 507-517.

Atkinson, L., \& Rosenthal, S. (2014). Signaling the green sell: The influence of eco-label source, argument specificity, and product involvement on consumer trust. Journal of Advertising, 43(1), 33-45.

Sønderskov, K. M., \& Daugbjerg, C. (2011). The state and consumer confidence in eco-labeling: organic labeling in Denmark, Sweden, The United Kingdom and The United States. Agriculture and human values, 28(4), 507-517.

Harms, R., Marinakis, Y., \& Walsh, S. T. (2015). Lean startup for materials ventures and other science-based ventures: under what conditions is it useful?. Translational materials research, 2(3), 035001.

Martinho, G., Pires, A., Portela, G., \& Fonseca, M. (2015). Factors affecting consumers' choices concerning sustainable packaging during product purchase and recycling. Resources, Conservation and Recycling, 103, 58-68.

Atkinson, L., \& Rosenthal, S. (2014). Signaling the green sell: The influence of eco-label source, argument specificity, and product involvement on consumer trust. Journal of Advertising, 43(1), 33-45

Sønderskov, K. M., \& Daugbjerg, C. (2011). The state and consumer confidence in eco-labeling: organic labeling in Denmark, Sweden, The United Kingdom and The United States. Agriculture and human values, 28(4), 507-517. 
Morwitz, V. G., Steckel, J. H., \& Gupta, A. (2007). When do purchase intentions predict sales?. International Journal of Forecasting, 23(3), 347-364.

Magnier, L., Mugge, R., \& Schoormans, J. (2019). Turning ocean garbage into products-Consumers' evaluations of products made of recycled ocean plastic. Journal of cleaner production, 215, 84-98.

Yeow, P., Dean, A., \& Tucker, D. (2013). Bags for Life: The Embedding of Ethical Consumerism. Journal Of Business Ethics, 125(1), 87-99. doi: 10.1007/s10551-013-1900-2

Yeow, P., Dean, A., \& Tucker, D. (2013). Bags for Life: The Embedding of Ethical Consumerism. Journal Of Business Ethics, 125(1), 87-99. doi: 10.1007/s10551-013-1900-2

Ramayah, T., Lee, J. W. C., \& Lim, S. (2012). Sustaining the environment through recycling: An empirical study. Journal of environmental management, 102, 141-147.

Sun, Y., Wang, S., Li, J., Zhao, D., \& Fan, J. (2017). Understanding consumers' intention to use plastic bags: using an extended theory of planned behaviour model. Natural Hazards, 89(3), 1327-1342. doi: 10.1007/s11069-0173022-0

Sun, Y., Wang, S., Li, J., Zhao, D., \& Fan, J. (2017). Understanding consumers' intention to use plastic bags: using an extended theory of planned behaviour model. Natural Hazards, 89(3), 1327-1342. doi: 10.1007/s11069-0173022-0

Oyedele, L. O., Ajayi, S. O., \& Kadiri, K. O. (2014). Use of recycled products in UK construction industry: An empirical investigation into critical impediments and strategies for improvement. Resources, Conservation and Recycling, 93, 23-31

Orset, C., Barret, N., \& Lemaire, A. (2017). How consumers of plastic water bottles are responding to environmental policies?. Waste Management, 61, 13-27. doi: 10.1016/j.wasman.2016.12.034

Orset, C., Barret, N., \& Lemaire, A. (2017). How consumers of plastic water bottles are responding to environmental policies?. Waste Management, 61, 13-27. doi: 10.1016/j.wasman.2016.12.034

Orset, C., Barret, N., \& Lemaire, A. (2017). How consumers of plastic water bottles are responding to environmental policies?. Waste Management, 61, 13-27. doi: 10.1016/j.wasman.2016.12.034

Hopewell, Jefferson, et al. "Plastics Recycling: Challenges and Opportunities." Philosophical Transactions: Biological Sciences, vol. 364, no. 1526, 2009, pp. 2115-2126. JSTOR, www.jstor.org/stable/40485985.

Hopewell, Jefferson, et al. "Plastics Recycling: Challenges and Opportunities." Philosophical Transactions: Biological Sciences, vol. 364, no. 1526, 2009, pp. 2115-2126. JSTOR, www.jstor.org/stable/40485985.

Orset, C., Barret, N., \& Lemaire, A. (2017). How consumers of plastic water bottles are responding to environmental policies?. Waste Management, 61, 13-27. doi: 10.1016/j.wasman.2016.12.034

Bennett, M., \& James, P. (Eds.). (1998). The green bottom line : Environmental accounting for management: current practice and future trends. Retrieved from https://ebookcentral.proquest.com

Bennett, M., \& James, P. (Eds.). (1998). The green bottom line : Environmental accounting for management: current practice and future trends. Retrieved from https://ebookcentral.proquest.com

Zettler, E. R., Mincer, T. J., \& Amaral-Zettler, L. A. (2013). Life in the "plastisphere": microbial communities on plastic marine debris. Environmental science \& technology, 47(13), 7137-7146.

Derraik, J. G. (2002). The pollution of the marine environment by plastic debris: a review. Marine pollution bulletin, 44(9), 842-852.

Betts, K. (2008). Why small plastic particles may pose a big problem in the oceans.

Ocean Conservancy, 2015. International Coastal Cleanup 2015 Report.

Adopt a Beach Program, 2015. Litter Report: Raw Data From Great Lakes Beach Cleanups. (Cigar tip percentage calculated by Jill Bartolotta, Ohio Sea Grant College Program and The Ohio State University Extension, May 19, 2016).

Bartolotta, J. F., \& Hardy, S. D. (2018, February). Barriers and benefits to desired behaviors for single use plastic items in northeast Ohio's Lake Erie basin. Retrieved from https://www.sciencedirect.com/science/article/pii/S0025326X17310706.

Bartolotta, J. F., \& Hardy, S. D. (2018, February). Barriers and benefits to desired behaviors for single use plastic items in northeast Ohio's Lake Erie basin. Retrieved from https://www.sciencedirect.com/science/article/pii/S0025326X17310706. 
Sauvé, S., Bernard, S., \& Sloan, P. (2016). Environmental sciences, sustainable development and circular economy: Alternative concepts for trans-disciplinary research. Environmental Development, 17, 48-56.

Malhotra, N., Hall, J., Shaw, M., \& Oppenheim, P. (2013). Marketing research: An applied orientation. Pearson Education. 